\title{
BIOMASS (SORGHUM AND MISCANTHUS) COMBUSTION PROCESS OPTIMISATION BY INFRARED FLAME ANALYSIS
}

by dr.eng. T. Prisecaru*, drd. eng. C. Ciobanu*, dr.eng. E. Pop*, dr.eng.M. Prisecaru*, dr.eng. I. Pisa*

* Politehnica University of Bucharest, Romania, tudor.prisecaru@upb.ro

\section{Abstract}

Biomass coming from the agricultural activities is more and used as a solid alternative fuel in small or medium industrial power generation. In this case both sorghum and miscanthus are not acclimatized plants in Romania. Due to the particular climate and soil conditions in Romania, many differences occurred between the Romanian sorghum and miscanthus and the original situations. All these aspects generated a long research activity to adapt classic combustion installations to be able to burn these two materials. Research presented here is focused upon optimisation of the combustion process of the Romanian sorghum and miscanthus separately to fit the emission limits for carbon monoxide and NOx.

\section{INTRODUCTION}

Starting with year 2000, several types of sorghum and miscanthus have been acclimatized and cultivated in Romania especially for industrial purposes such as the ones presented in Table 1.

Table 1. Types of sorghum and miscanthus cultivated in Romania

\begin{tabular}{|l|l|l|}
\hline Name & $\begin{array}{l}\text { Cultivated surface } \\
\text { hectares }\end{array}$ & $\begin{array}{l}\text { Production } \\
\text { t/ha }\end{array}$ \\
\hline Miscanthus giganteus & $1,000-5,000$ & $18,5-22,5$ \\
\hline Sorghum X Sudan & $10,000-25,000$ & $15-30$ \\
\hline Sudan herb & about 25,000 & $10-20$ \\
\hline Sorghum saccharatum & $<5,000$ & $10-35$ \\
\hline
\end{tabular}

The favorable areas for cultivation of fiber flax are the inter-Carpathian depressions and the Black Sea coast (a broad strip of 10-20 km). As far as sorghum is concerned, such crops have a great potential in Romania from the standpoint of both cultivation opportunities and plant features (38-45\% content of crude cellulose). Unfortunately, up to 2010 , sorghum was used in Romania only as fodder and material for making brooms and other handicrafts [1], [2]. Since 2010 many research activities have been started aiming to ensure the energy recovery of technical sorghum, sorghum saccharatum and miscanthus giganteus. Due to this fact, the Thermal Equipment Laboratory in the Politehnica University of Bucharest has developed an experimental basis capable of analyzing many technologies and many types of special systems to burn and gasify vegetal biomass. This experimental basis comprises a group of boilers characterized by different levels of power and automation degrees to cover almost the whole range of useful situations together with a complete set of analytical instruments to sort out the quantitative chemical compositions of solid fuels, flue gas and wastes. At the same time, some infrared research equipment has been added in order to study flame characteristics and ignition patterns.

\section{CHEMICAL QUANTITATIVE RESEARCH ON ROMANIAN ACCLIMATIZED SORGHUM}

Our studies regarding the energy recover of Romanian sorghum started with several elemental chemical analyses. Due to the fact that the plant structure features three main components - stems, leaves and panicles - this approach was based on an elemental analysis for each of the two sorts. This decision was made in compliance with the ultimate project aim of using this type of biomass - as pellets or briquettes, after previous to shred. The elemental analysis has been carried out with the aid of a COSTECH ECS 4010 apparatus featuring the technical specifications listed on the site www.costechanalytical.com. This apparatus uses the principles of gas chromatography of the combustion products of solid biomass. An ordinary analysis is composed of two stages: the first one to determine the carbon, hydrogen, nitrogen and 
sulphur content while the second one is used to determine the elementary oxygen. A supplementary analysis determines the ash and humidity content separately.

For each of the plant components (stem, leaves and panicles) a number of 100 samples characterized by masses between 1.5 to $4.0 \mathrm{mg}$ have been provided. A total number of 600 samples have been analyzed for both two sorghum sorts: SORGHUM 1 (technical) and SORGHUM 2 (saccharatum). Based upon a mediation operation applied to the resulting values one has drawn up Tables 2 and 3.

Table 2. Elemental analysis for SORGHUM 1

\begin{tabular}{|l|l|l|l|l|l|l|l|l|l|}
\hline \multirow{2}{*}{ SORGHUM 1 } & $\mathrm{Wt}$ & $\mathrm{C}$ & $\mathrm{H}$ & $\mathrm{N}$ & $\mathrm{S}$ & $\mathrm{O}$ & $\mathrm{A}$ & $\mathrm{Q}_{\mathrm{an}}$ & $\mathrm{Q}_{\text {lex }}$ \\
\cline { 2 - 10 } & $\%$ & $\%$ & $\%$ & $\%$ & $\%$ & $\%$ & $\%$ & $\mathrm{~kJ} / \mathrm{kg}$ & $\mathrm{kJ} / \mathrm{kg}$ \\
\hline Leaves & 9.08 & 44.7 & 5.8 & 2 & - & 28 & 10.42 & 17847 & 17868 \\
\hline Panicles & 14.2 & 44.8 & 5.7 & 1.4 & - & 28.5 & 5.4 & 17595 & 17627 \\
\hline Stems & 43.5 & 22.1 & 7.1 & 0.2 & - & 25.8 & 1.3 & 10900 & 10861 \\
\hline
\end{tabular}

Where: $\mathrm{Wt}$ - humidity content, C- carbon content, $\mathrm{H}$ - hydrogen content, $\mathrm{N}$ - nitrogen content, S- sulphur content, O- oxygen content, A- ash content, $Q_{1}$ an - low heating value by elemental analysis, $Q_{1 e x}-$ low heating value by calorimetric bomb.

Table 3. Elemental analysis for SORGHUM 2

\begin{tabular}{|r|r|r|r|r|r|r|r|r|r|}
\hline SORGHUM 2 & $\mathrm{Wt}$ & $\mathrm{C}$ & $\mathrm{H}$ & $\mathrm{N}$ & $\mathrm{S}$ & $\mathrm{O}$ & $\mathrm{A}$ & $\mathrm{Q}_{\text {lan }}$ & $\mathrm{Q}_{\text {lex }}$ \\
\cline { 2 - 9 } & $\%$ & $\%$ & $\%$ & $\%$ & $\%$ & $\%$ & $\%$ & $\mathrm{~kJ} / \mathrm{kg}$ & $\mathrm{kJ} / \mathrm{kg}$ \\
\hline Leaves & 11.66 & 45.4 & 5.8 & 1.1 & - & 27.5 & 8.54 & 18074 & 18098 \\
\hline Panicles & 12.45 & 44 & 6.1 & 1.7 & - & 32.9 & 2.85 & 17300 & 17332 \\
\hline Stems & 38.18 & 27.9 & 7.8 & 0.2 & - & 23.6 & 2.32 & 13961 & 13917 \\
\hline
\end{tabular}

The low heating values of the samples have been determined with a calorimetric bomb PARR 6200 featuring the technical specification listed on http://www.preiser.com/90-4062-01parrisoperibolcalorimetermodel6200ea115v.aspx. Q lex $_{\text {. }}$ value has been verified according to standards lest it should not exceed by more than $50 \mathrm{~kJ} / \mathrm{kg}$ the value resulting from the Mendeleev-Dulong statistical relation. For the calorimetric bomb 3 samples / structural element have been prepared between 0.6 and 1.2 grams each.

As can be seen from Table 2 and 3, the most special structure belongs to the sorghum stem due to its very high humidity content compared to the other components. At the same time, the lowest ash content can be seen in the panicles. The most important comment refers to the natural drying procedures, as both sorghum types have to be dried by a natural process along a period of two weeks; this operation has been made necessary by the very high initial humidity. On the other hand, using a forced drying procedure could waste some volatile biomass components. Another important fact is about the sulphur missing from all the structural elements. All the values presented in Tables 2 and $\mathbf{3}$ are similar with literature values [3] [4].

\section{CHEMICAL QUANTITATIVE RESEARCH ON ROMANIAN ACCLIMATIZED SORGHUM}

Similar qualitative investigations have been performed upon one hundred samples of Miscanthus Giganteus cultivated on two Romanian areas (Covasna - Middle Romania and Great Island of Braila - on Danube); all these results are presented in the Table 4.

Table 4. Elemental analysis for Miscanthus Giganteus

\begin{tabular}{|r|r|r|r|r|r|r|r|r|r|}
\hline Miscanthus & $\mathrm{Wt}$ & $\mathrm{C}$ & $\mathrm{H}$ & $\mathrm{N}$ & $\mathrm{S}$ & $\mathrm{O}$ & $\mathrm{A}$ & $\mathrm{Q}_{\mathrm{lan}}$ & $\mathrm{Q}_{\mathrm{lex}}$ \\
\cline { 2 - 10 } giganteus & $\%$ & $\%$ & $\%$ & $\%$ & $\%$ & $\%$ & $\%$ & $\mathrm{~kJ} / \mathrm{kg}$ & $\mathrm{kJ} / \mathrm{kg}$ \\
\hline Pieces & 11.04 & 41.71 & 5.61 & 0.62 & 0.00 & 32.72 & 8.30 & 15300 & 15283 \\
\hline
\end{tabular}

As it can be seen there is a quasi - similitude between the Sorghum 2 leaves composition and that one belonging to Romanian Miscanthus. Within the Figure $1(a, b)$ a sample of a representative elementary analysis of the Miscanthus Giganteus is presented.

\section{EXPERIMENTAL SYSTEMS}

To test out the combustion possibilities of Romanian sorghum, two practical procedures have been adopted: bulk burning and shredded form burning. For bulk burning sorghum, a $55 \mathrm{~kW}$ PIFATI boiler has been used as this type is provided with both liquid fuel burner and solid fuel combustion grate (Figure 2). 


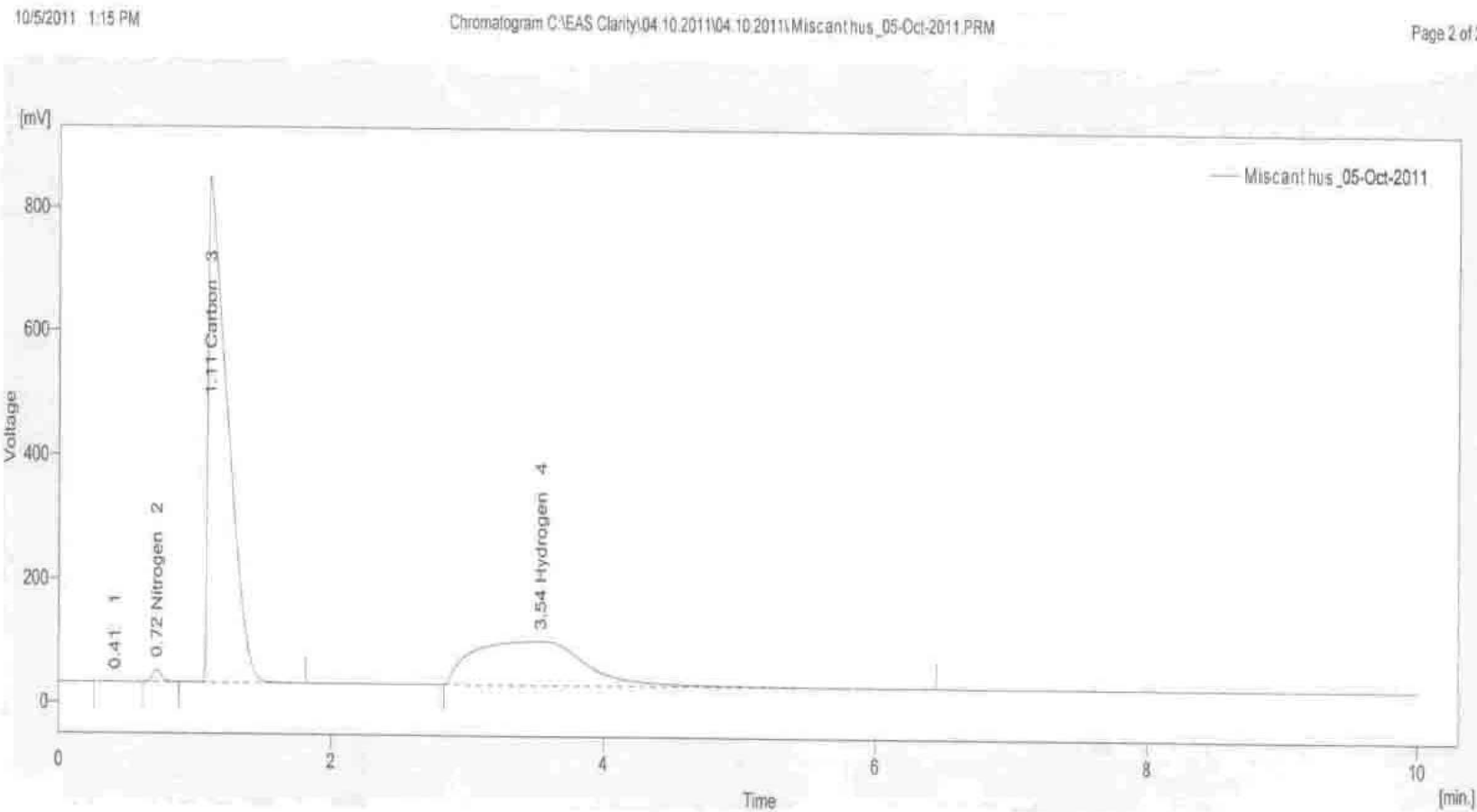

Result Table (ESTO - Miscanthus_.05-0at:2011)

\begin{tabular}{|c|c|c|c|c|c|c|c|}
\hline & $\begin{array}{l}\text { Relen. Time } \\
\text { [min] }\end{array}$ & Response & $\begin{array}{c}\text { Weight } \\
\text { [mgl }\end{array}$ & $\begin{array}{c}\text { Weight } \\
[\%]]\end{array}$ & $\begin{array}{l}\text { Peak: } \\
\text { Type }\end{array}$ & $\begin{array}{l}\text { Element } \\
\text { Name }\end{array}$ & $\begin{array}{c}\text { Carbon Response } \\
\text { Ratia }\end{array}$ \\
\hline 1 & 0.407 & 5069 & 0.000 & 0.0 & & & \\
\hline 2 & 0,717 & 88.504 & 0035 & 0.50 & Refer & Nitrogen & 0.011 \\
\hline 3 & 1.110 & 7883480 & 1.435 & 41,80 & Refer & Carbon & 1000 \\
\hline \multirow[t]{2}{*}{4} & 3537 & 4113954 & 0.183 & 5.41 & Refer & Hydrogen & 0515 \\
\hline & Total & & 3.161 & 47.81 & & & \\
\hline
\end{tabular}

11/12011 3.54 PM

Chromatogram C.IEAS Ciarity01.11.2011101.11.20111Miscantus_01_2011 03_44_10 PM_020.PRM

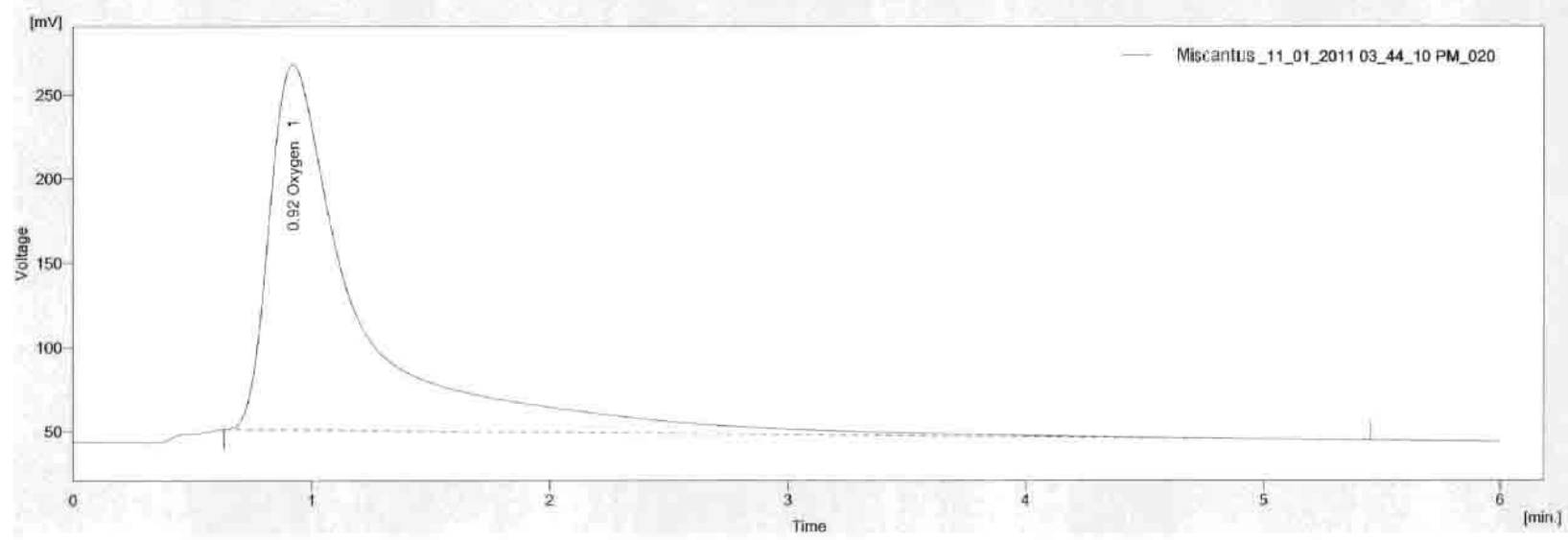

\begin{tabular}{|c|c|c|c|c|c|c|c|}
\hline & $\begin{array}{c}\text { Reten. Time } \\
\text { [min! }\end{array}$ & Response & $\begin{array}{c}\text { Weight } \\
\text { [mg] }\end{array}$ & $\begin{array}{l}\text { Weight } \\
{[\%]}\end{array}$ & $\begin{array}{l}\text { Peak } \\
\text { Type }\end{array}$ & $\begin{array}{l}\text { Element } \\
\text { Name }\end{array}$ & $\begin{array}{l}\text { Carton Response } \\
\text { Ratio }\end{array}$ \\
\hline 1 & 0.923 & 5766,193 & 0.864 & 33.82 & Refer & Oxygen & \\
\hline & Total & & 3141 & 33.82 & & & \\
\hline
\end{tabular}

Fig.1. Elementary analysis of one of Miscanthus sample; up - a - carbon, nitrogen, and hydrogen; down- $b$ - oxygen content. 


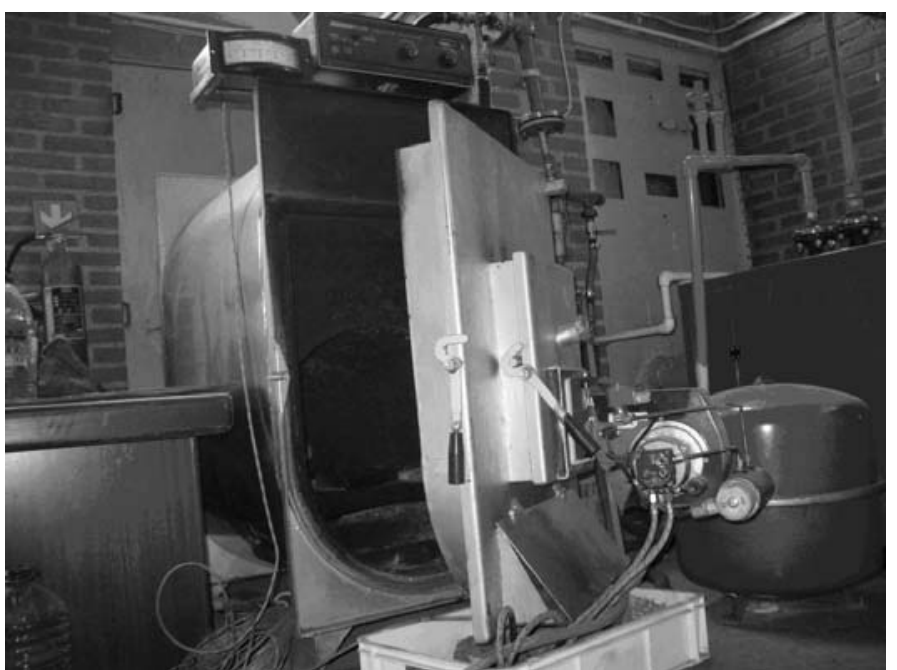

Fig. 2. PIFATI boiler of $55 \mathrm{~kW}$ - here both the liquid fuel burner and the grated solid fuel furnace can be seen together

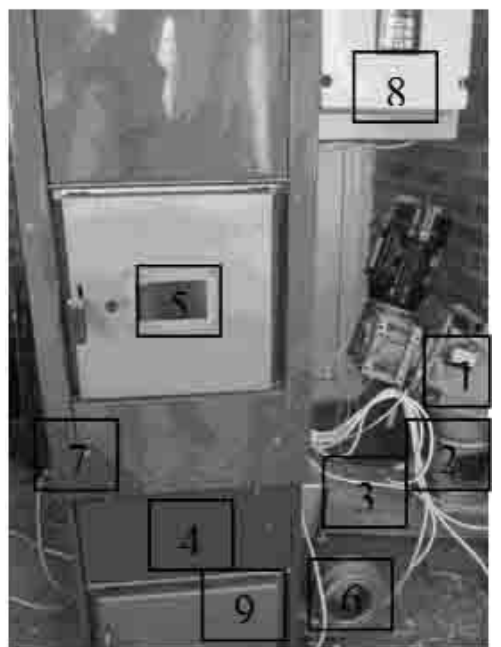

Fig. 3. ERPEK boiler prepared for tests

The burning procedure involved fuelling the burner with sorghum type fuel, starting ignition by using liquid fuel and allowing the combustion process proceed without adding any more liquid fuel. To burn the biomass under shredded form a special drum cutter has been used in the first place. All the biomass has been crushed to an average dimension of $10 \mathrm{~mm}$.

To burn the shredded miscanthus the same procedure has been used with the single difference that the pieces have been processed at about $50 \mathrm{~mm}$ as an average dimension. Then a $50 \mathrm{~kW}$ ERPEK boiler has been used, like that one presented in the Figure 3. As can be seen from figure 3, the whole boiler is fully automate and the system is composed of the fuel container (not visible in the figure 3 but in the fig.6) where the fuel is taken by feeder 1 , sent to dispenser 2 and then sent by a gear mechanism to furnace 4 . The combustion process can be visualized through window 5 . Ventilator 6 supplies the necessary air flow rate to the Lambda sample probe 7. The fuel flow rate can be controlled in stages from panel 8 . The furnace door can be opened for direct process monitoring. Ash is collected in bottom drawer 9 . Here Miscanthus has been cut in small pieces of about $10 \mathrm{~mm}$ in order to be operated by the gear mechanism.

\section{DIRECT BURNING METHODOLOGY FOR SORGHUM}

First, the bulk material has been introduced into the $55 \mathrm{~kW}$ PIFATI boiler and has been ignited with liquid fuel through the injector.

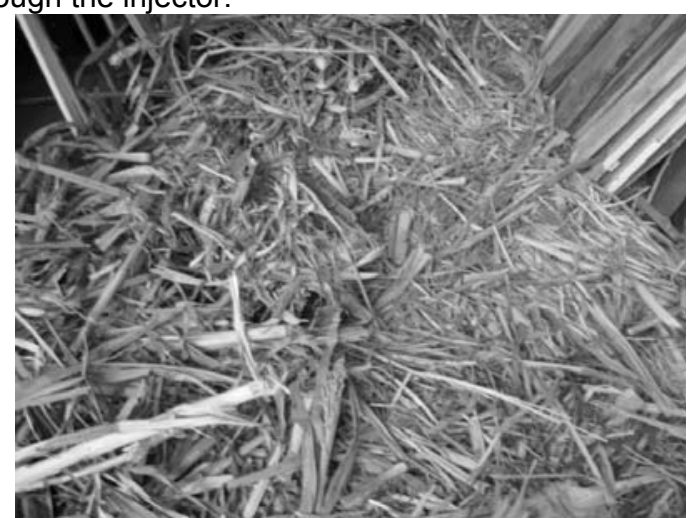

Fig. 4. Bulk sorghum

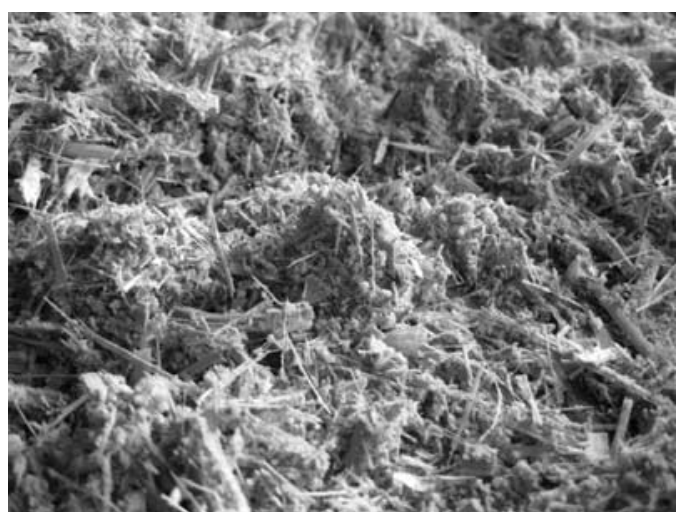

Fig. 5. Shredded sorghum prepared for burning

The bulk material of sorghum 1 and 2 looks as shown in Figure 4; it has been structured into the three components and then remixed. In this case, the combustion process cases immediately after the liquid fuel ignition procedure is off. When analyzing the state of the furnace, a thick condensed humidity layer was seen and a very great part of the fuel interchange 
area with the oxygen was also covered by humidity thus, the chemical oxidation reaction could not take place. The same phenomenon was seen when the crushed sorghum was tested, namely a condensed thin water layer had covered the whole surface of the fuel (Figure 5).

As a general observation, the humid layer was much thicker in the shredded material than in the bulk biomass. Due to this very high humidity content, a staged natural drying procedure was taken into account together with a periodical test of the ignition capacity.

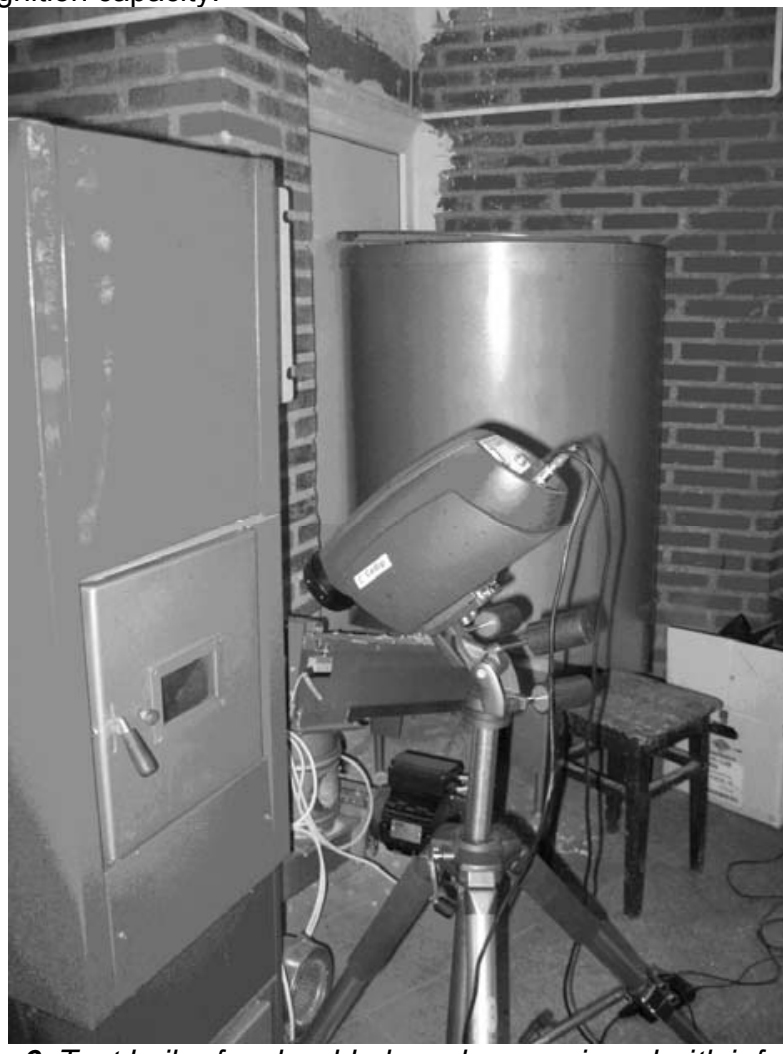

Fig. 6. Test boiler for shredded sorghum equipped with infrared monitoring system
The drying procedure was performed in a suitable room and the ignition test period was reconsidered at every three days. As can be seen from Figure 6, a quartz window was used to allow the CEDIP Silver 420 infrared video camera to record the combustion parameters and two gas analyzers HORIBA PG 250 and AFRISO Maxilizer were also been used to record the flue gas composition.

The recorded data from HORIBA PG 250 have been graphically presented in Figure 7 SORGHUM 1 and Figure 8 SORGHUM 2. All these data show that the combustion process did not have a normal run and it has been limited to slight gasification due to a very small interchange area between the biomass and the oxygen. Time has been given in seconds and the process data collection rate was every five seconds.

By contrast, the carbon monoxide concentration has been very high - exceeding the apparatus range of $10000 \mathrm{ppm}$. At the same time, very reduced values of carbon dioxide concentration have been recorded in opposition to very high oxygen content in the flue gas. The corrected infrared image of the furnace also indicated a range of low flame temperature values (Figure 9). All these data have been explained by the high superficial moisture content which have blocked up all the porous channels through the combustion material and have decreased the contact surface with the oxygen.
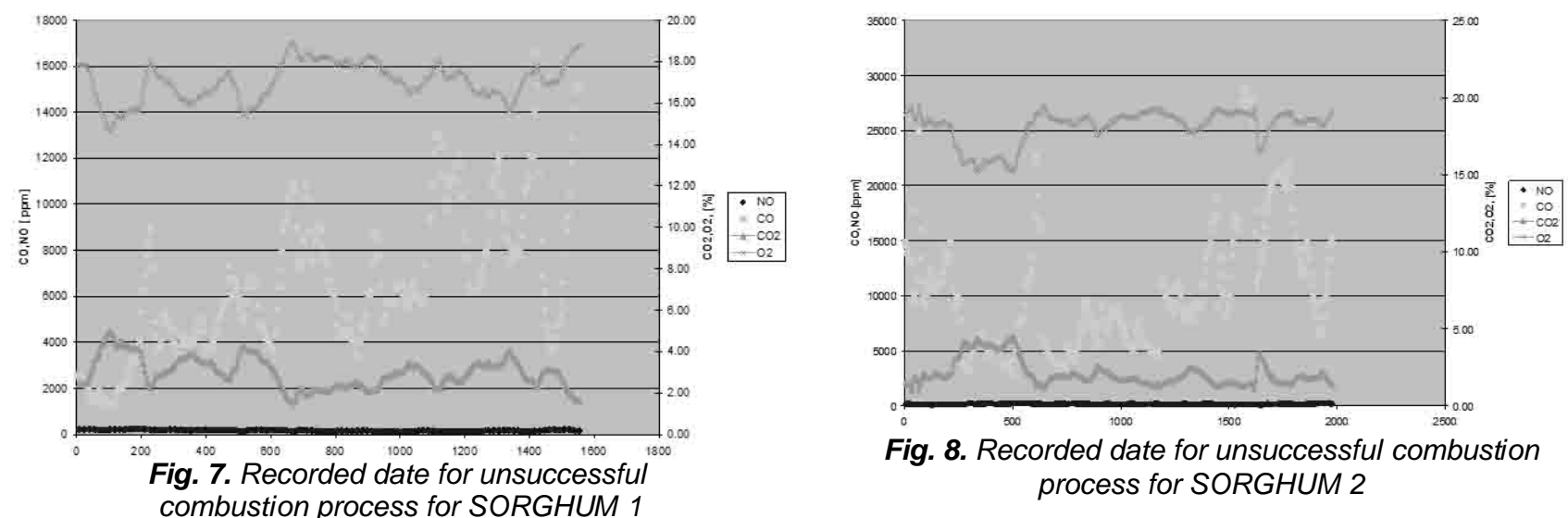

Fig. 8. Recorded date for unsuccessful combustion process for SORGHUM 2

The NOx concentration values are very low due to the very low values of recorded temperature. By contrast, the carbon monoxide concentration has been very high - exceeding the apparatus range of 10000 ppm. At the same time, very reduced values of carbon dioxide concentration have been recorded in opposition to very high oxygen content in the flue gas. The corrected infrared image of the furnace also indicated a range of low flame temperature values (Figure 9). 


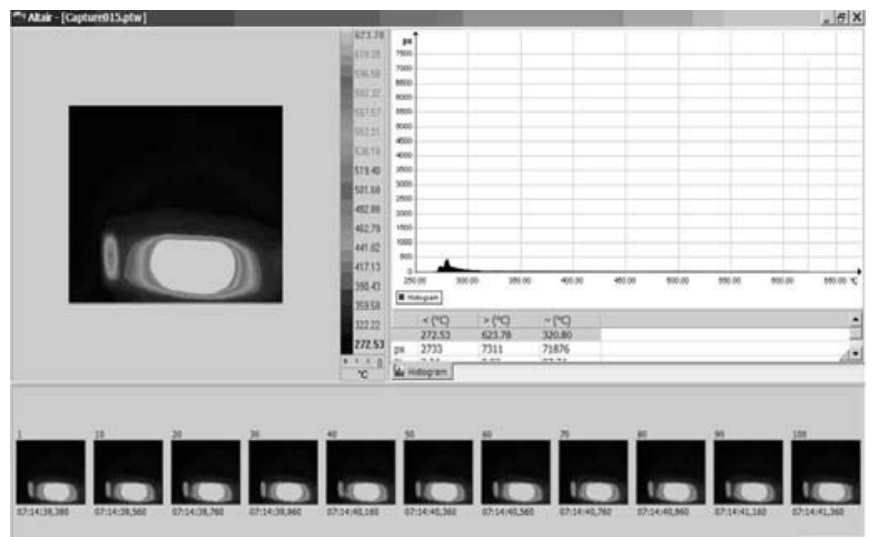

Fig. 9. Infrared images for sorghum flame with gasification

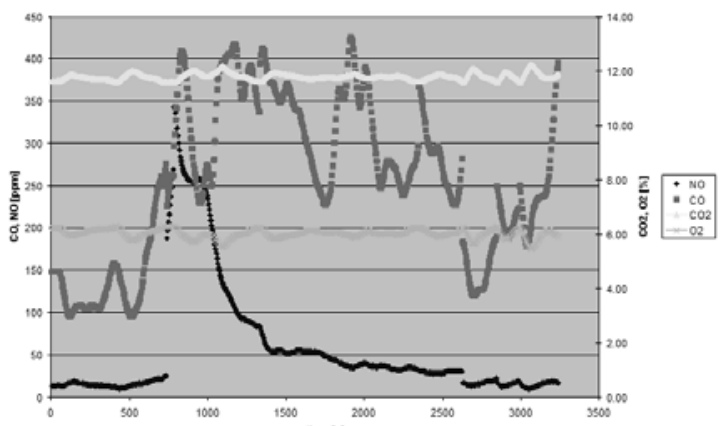

Fig. 10. Recorded date for flue gas composition in case of successful combustion process for SORGHUM 1

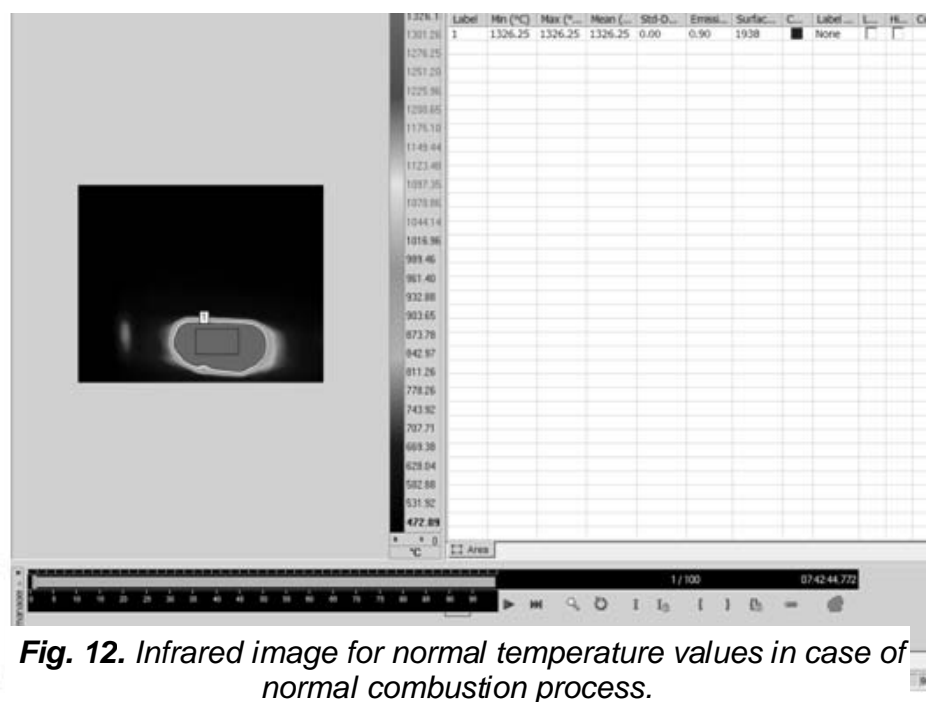

As it can be seen from the Fig.9, the range of the temperatures is very small and the process reaches the characteristics of a gasification or pirolysis due to the effect of the great quantity of moisture. The infrared camera has been set to the following wave lengths: $2.5-2.99 \mu \mathrm{m}$; $5.26-$ $8.33 \mu \mathrm{m}$ and 13.4-18.3 $\mu \mathrm{m}$ [5]. These ranges allowed to track the emissions from the carbon dioxide and water vapors and to record them.

When the total humidity content was lower than $17.8 \%$ for SORGHUM 1 and $17.65 \%$ for SORGHUM 2, the combustion process started to become normal [6].

Recordings for these two tests carried on the $50 \mathrm{~kW}$ PIFATI boiler are shown in Figure 10 and 11.

That it can be seen in the two graphs, the carbon monoxide concentration values are very small in comparison to the first situation.

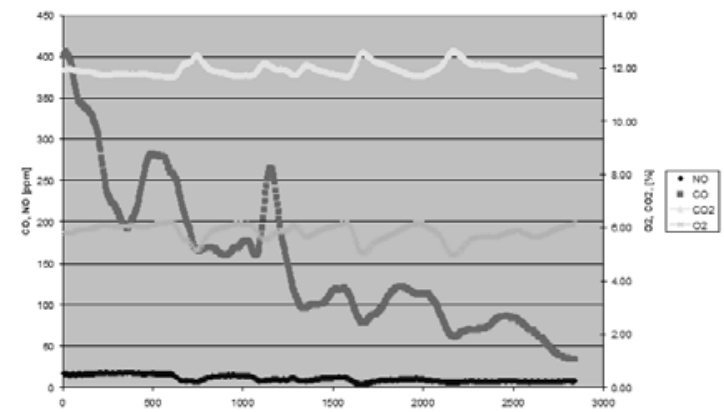

Fig. 11. Recorded date for flue gas composition in case of successful combustion process for SORGHUM

2

Due to the limited possibilities of varying the thermal load on the $50 \mathrm{~kW}$ PIFATI boiler, some high values of the carbon monoxide have occurred during load modulations and this boiler has not been used for further experiments on the second type of sorghum.

With SORGHUM 2, tests started from the maximum load to the minimum one and results were better distributed according to existing standards. The main conclusion is that this type of furnace is very good for sorghum burning with loads below $30 \mathrm{~kW}$, the carbon monoxide emission being below $100 \mathrm{ppm}$. The infrared images of this type of flame also feature very normal temperatures for a combustion process (Figure 12).

At the same time, the carbon dioxide concentrations are above $11 \%$ and the oxygen concentration is lower than $6.5 \%$.

\section{MISCANTHUS GIGANTEUS DIRECT COMBUSTION METHODOLOGY}

When pieces of Miscanthus Giganteus have been prepared for the direct burning tests a lot of supplementary measures had been considered before. Its humidity has been conserved by keeping it in a climatisated storage room and more than this the shredding procedures have been realized in the same room.

Tests have been considered using two values for the excess of the air:1.8 and 1.3 and both of them have been performed on the ERPEK boiler. For the two representative cases two pictures have been recorded with the infrared camera and they are presented in the fig. 13 and Fig.14. The same settings for the camera have been preserved. 


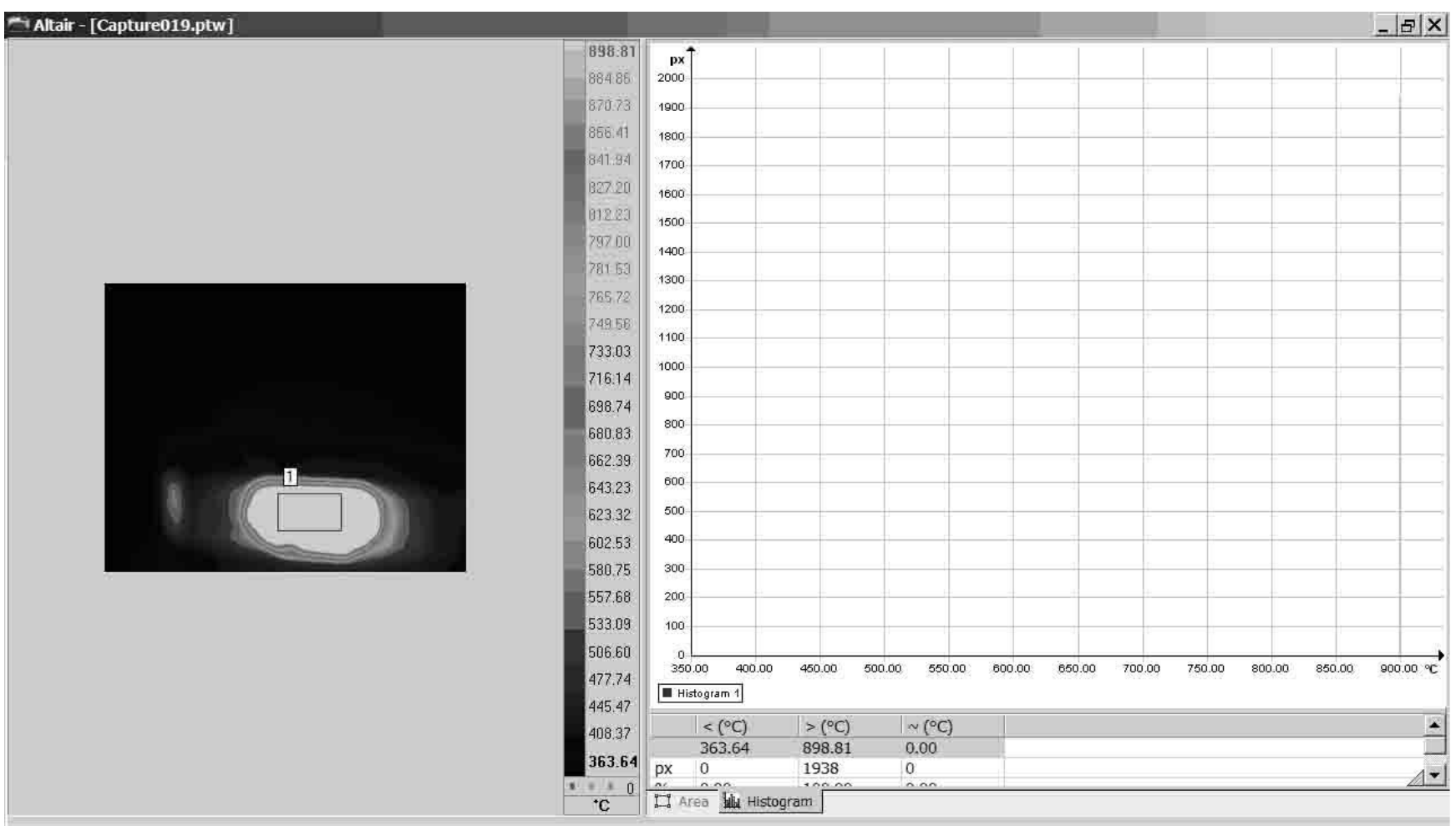

Fig.13. Miscanthus Giganteus combustion tests using the excess of air equal with 1.8

The main difference between the two cases was represented by the temperature which was higher when the lower excess of air was used. At the same time the NOx was lower than the admissible values in both cases.

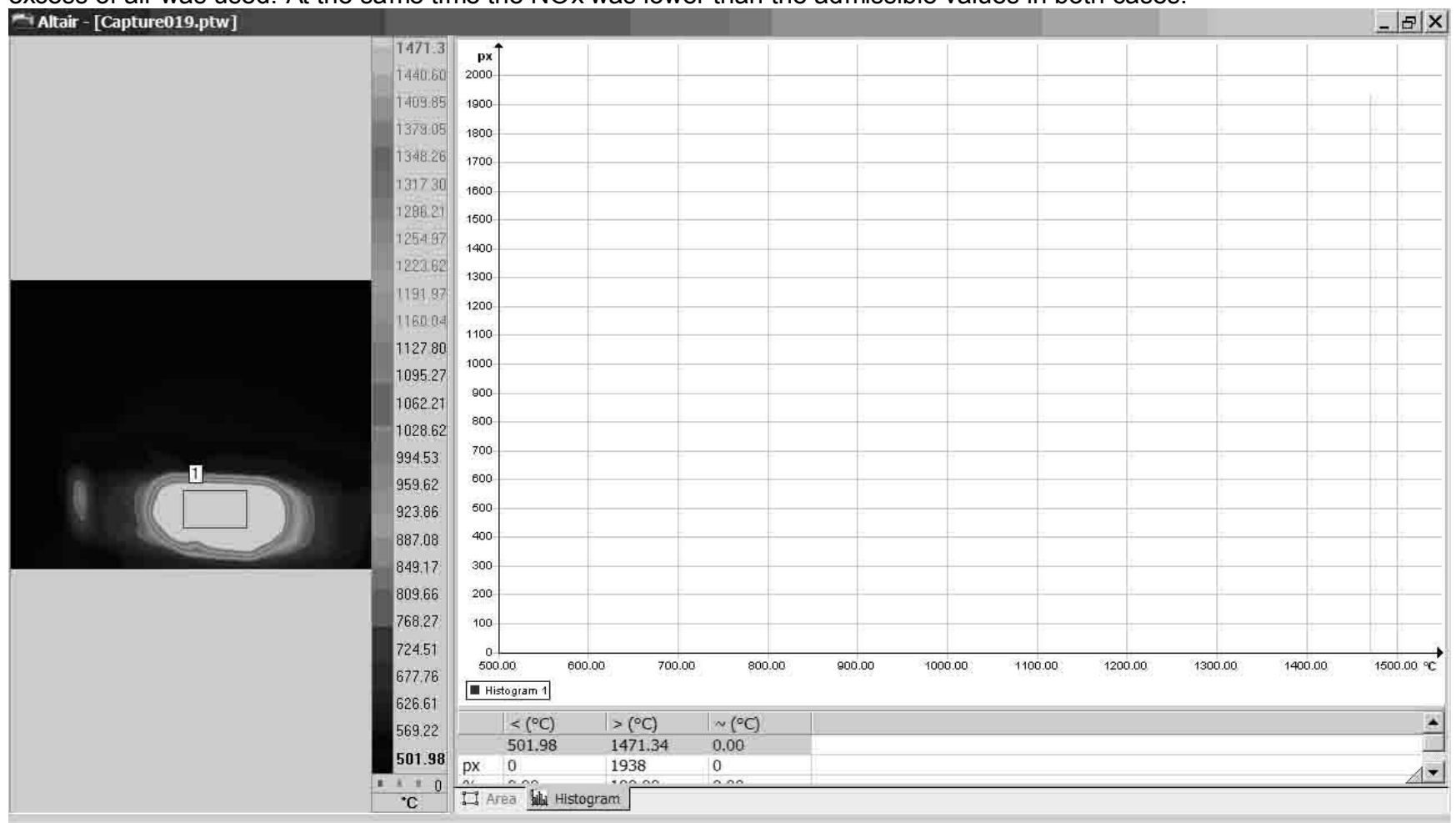

Fig.14. Miscanthus Giganteus combustion tests using the excess of air equal with 1.3. 
The carbon monoxide has been found at high values when air excess has been equal with 1.8 (approximately 1400 ppm in the furnace) being higher than the admissible limit.

\section{CONCLUSIONS}

1. Any type of Romanian sorghum can be directly burned if its humidity content is lower than $17.5 \%$

2. The best technical solution for burning Romanian shredded sorghum is mix combustion in suspension over the grate; this solution can be implemented with a mechanical centrifugal thrower which throws the fuel according to parabolic trajectories; the fuel is partially burned and then it falls on a mobile grate having a reversed translation motion compared to the centrifugal thrower where the burning process is finalized.

3. At load above $10 \mathrm{MW}$ the mobile grate can be replaced by a fixed one due to large dimensions of the furnace which allows a partial combustion in suspension.

4. Miscanthus Giganteus can be normally burned in suspension if the pieces are lower than $15 \mathrm{~mm}$ and using an air excess lower than 1.67. The team reached this value performing many tests and registering the carbon monoxide values to be under the $100 \mathrm{ppm}$.

\section{ACKNOWLEDGEMENTS}

The authors would like to thank to the Green Energy Association members and Biofuels Association members both from Romania for helping the experimental work to this paper and for the critical analysis of the obtained results. At the same time the authors would like to thank to the technical staff of the ETCN- Politehnica University laboratory for the heavy duty to prepare the whole quantity of biomass in order to be tested.

The work has been funded by the Sectoral Operational Programme Human Resources Development 20072013 of the Romanian Ministry of Labour, Family and Social Protection through the Financial Agreement POSDRU/107/1.5/S/76909.

\section{REFERENCES}

[1] G. Pintilie, M. Moscovici, Interactive European Network for Industrial Crops and their Applications. Forming Part of the IENICA-INFORRM Project. Romanian Report.Tthe Fifth Framework Programme by DG XII, Bucharest, 2004.

[2] Velcescu B., Staicu M., The Potential of Romanian Agriculture for Energy Crops, BIOENERGY in EU countries - Current Status and Future Trends, Cluj-Napoca, România, USAMV, May 2011.

[3] C.R. Cardoso , a.o., Determination of kinetic parameters and analytical pyrolysis of tobacco waste and sorghum bagasse, Journal of Analytical and Applied Pyrolysis, Vol. 92, Iss. 2, Nov. 2011, pp. 392-400.

[4] L. Barbanti, a.o., Sweet and fibre sorghum (Sorghum bicolor (L.) Moench), energy crops in the frame of environmental protection from excessive nitrogen loads, European Journal of Agronomy, Vol. 25, Iss. 1, July 2006, pp. 30-39.

[5] Rothman L.S. et al., The HITRAN 2008 molecular spectroscopic database, Journal of Quantitative Spectroscopy and Radiative Transfer, Vol.100, 2009, pp. 533-572

[6] J. F. Gonzáleza, a.o. , Use of energy crops for domestic heating with a mural boiler, Fuel Processing Technology, Vol. 87, Iss. 8, August 2006, pp 717-726. 